causes of fires on steamships in bunkers and cargo coal, are sufficient evidence of the important contributions made in every field of transport, without enumerating the metallurgical research or the important engineering investigations carried out at the National Physical Laboratory.

In another field of communications, the Radio Research Board is making contributions which affect the millions of homes where broadcasting is received, while dental research, the production of insecticides for the destruction of the cocoa moth, the production of new drugs, and the discovery of the efficiency of borax-boric acid mixtures for the fireproofing of fabrics-and investigations on the action of sunlight on cotton, which have revealed the deleterious effect of small traces of iron, are all that can be mentioned of the activities of the Fabrics Research Board.
Similar work is being carried out in Canada, Australia, New Zealand, South Africa, and in certain fields, notably in that of the transport of fruit and on the investigation of Empire timbers, much has already been done to secure co-operation between the mother country and the Dominions overseas. Even the above brief survey should make it sufficiently clear that the work of the Department of Scientific and Industrial Research is a vital factor in the prosperity of the British Empire, and upon its wise direction and active prosecution depend in large measure our prospects of restoring our industries to full vigour, exploiting to the full such natural advantages as we possess, and, by increased efficiency where we now possess no such advantages, recovering something of the position we formerly held amongst the industrial nations of the world.

\title{
Physical and Mental Development of Children.
}

$\mathrm{I}^{\mathrm{N}}$ spite of the assiduity with which the growing child has been studied within recent years, it cannot be said that we know very much about him. But what we do know, and know with any degree of scientific certainty, is set forth in the Report of the Consultative Committee on the Primary School* recently issued. The Committee, indeed, has spared no pains in securing the most trustworthy information at present available. It has interviewed eighty-nine witnesses; it has read a staggering number of memoranda; it has examined with special care all evidence which can claim scientific validity. Hence it has treated with special respect the opinions of physiologists and psychologists. Indeed, much of what is said in the body of the Report about the development of the child is based on two memoranda which are printed in full in the appendix. The first is by Prof. H. A. Harris on the physical development of the child, and the second by Prof. Cyril Burt on the mental development of the child.

Prof. Burt's memorandum will be dealt with first. It may be said at once that it is wholly admirable. It sets forth with great clearness, and with no small measure of charm, all that is certainly known about the psychology of the child of primary school age-all that would receive the unqualified support of the author's fellow psychologists in Europe and America. It indicates the views that have survived; and these views show how far we have moved within the last thirty years.

Thirty years ago, the orthodox creed was largely based on biology. The belief of what happened in the mind was mixed up with a belief of what happened in the body and in its remote progenitors. It was believed that in the growing child certain instincts and interests and powers remained virtually dormant up to a given age, and then suddenly woke up and became insistently active. Their maturation was almost as sudden as their birth. Thus definite layers of mental life were laid down and consolidated, and, on top of these, new layers

" "The Primary School." (London: H.M. Stationery Office, 1931.) 28. 6d. net.

No. 3206, VoL. 127] were superimposed. First came the mastery of the physical senses, then the control of the muscular system (including the muscles of speech), which give rise to walking, dancing, talking, and constructing things with the fingers. Then came the development of memory, and finally the emergence of a capacity to reason.

Mixed up with this stratification theory, as Prof. Burt calls it, is the recapitulation theory, which states that the development of the child tends to reproduce in rapid and abbreviated form the evolution of the race. He goes through the cavedwelling period, the savage period, and the barbarian period. $\mathrm{He}$ is at various times in the hunting stage, the nomadic stage, the agricultural stage, the craft stage, and what not.

We no longer hold these views-not in their original form at any rate. The stratification theory is discredited by the fact that experiment has exploded the old doctrine of distinct faculties, such as memory and reason; and the recapitulation theory is discredited by the failure to find evidence for the transmission of personally acquired characters. There is no more reason to think that the son of a potter inherits the aptitudes and interests of a potter (apart, that is, from the influences of his immediate environment) than there is for believing that the son of a mathematician will know the differential calculus by the light of Nature. Indeed, these old beliefs have been shattered through their failure to fit in with the facts of the mental life which have been disclosed by direct observation and experiment. For the method of direct study is essentially the modern method.

This is an important point of methodology. The child's mind is studied, not by studying his body, his brain, or his pedigree, but by the simple and obvious method of studying the thing itself. The facts to be observed and explained are mental facts. Real progress in the study of mental development may be said to have begun when the psychologist resolutely turned a blind eye to the alluring theories of the physiologist or the 
anthropologist, and began to study the mind as a mind. It was Binet who set the investigator on the right track. His instrument of research was neither a scalpel nor a microscope, but a mental test-a simple examination question, so devised, so applied, and so interpreted, as to become at once a means of discovery and a means of measurement. Indeed, all we know with certainty about the mode and rate of development of the child mind is a result of the direct method of mental testing.

This is abundantly evident from Prof. Burt's memorandum. He shows how, by the modern method, it is demonstrated that general intelligence grows with age, that the so-called faculties are all mixed up together from the very start, and that special intellectual interests and abilities develop, though they do not begin, at successive ages of school life. The new findings wholly fail to confirm the old theories. There is no ground for the old belief that memory is stronger at the junior school period than at any other; nor yet for the old belief that children cannot reason until they reach the adolescent stage. Children of all ages are found to reason well enough within the range of their understanding.

Prof. Harris's memorandum is equally good of its kind ; but is different in kind: It has more of personal theory and conjecture; it pushes out further into the realm of the unexplored.. 'For this very reason, some of his views, interesting and suggestive as they are, must be accepted with caution. He lays much stress upon successive periods of springing-up and of filling-out that occur in the course of a child's growth. The child mainly grows in height at one period and mainly grows in weight at another. There are, according to Dr. Harris, three of each period. The second springingup period, for example, takes place during the ages of five, six, and seven years ; and the second fillingout period during the ages of eight, nine, and ten. The curves of growth, however (one for height and one for weight), which he publishes in his memorandum, afford but slight evidence of these periods. Indeed, he admits that his inferences are drawn from clinical observations rather than from the curves of growth.

The existence of this rhythm is not denied ; nor is the importance that Prof. Harris attaches to a recognition of this rhythm; but what is in doubt is whether it follows such simple laws as his classification suggests. A letter is at hand from a schoolmaster in Lancashire, who for many years made careful and regular measurements of his daughter's increase in height. For many years, beginning at the age of three, she grew at the rate of two inches a year-one inch in April and another inch in October-her stature being practically constant for the remaining months of the year. During the two growing months, she was mentally inert ; and during the two months that respectively followed she often succumbed to the various ill. nesses incident to childhood. This, of course, is only one case ; but other similar ones might be mentioned, which at least indicate that the rhythm is to a large extent individual and personal. If there is a wide wave of tendency over a long period, there are many ripples on the wave.

Prof. Harris shows clearly that sex differences appear all along the line, and not merely at adolescence. Indeed, it has long been an accepted fact that in the matter of physiological age, as judged by the eruption of teeth, the ossification of the wrist bones, and the onset of puberty, there is a difference between the two sexes which at the age of eleven amounts to about two years. Anatomically, a girl of eleven is at the same stage as a boy of thirteen. Here we find a clash of opinion between the physiologist and the psychologist. While the physiologist proclaims a wide disparity between the development of boys and the development of girls, the psychologist just as confidently proclaims their identity. He tells us that neither in the level nor in the rate of intellectual development is there any appreciable difference between boys and girls. There are emotional differences, and differences of interest; but no difference in general intellectual power. The truth, of course, is that each class of statements is valid in its own sphere. As boys and girls differ in muscular development, they should play apart; as they roughly agree in intellectual development, they may study together.

Each class of statement is valid in its own sphere ; and Prof. Harris's valuable memorandum will be read with much interest and profit by all concerned with the nurture of the young. It is illustrated by excellent photographs ; it is enlivened by wise and epigrammatic sayings ; it is abundantly provocative of thought. It is only when he leaves his own territory and would base psychology on physiological facts that we join issue with him. He says, for example : " All growth and proliferation on the one hand and all differentiation for special function on the other will probably be found to be the ultimate basis of a rational psychology, whether it be labelled 'Gestalt' or not". As a pious belief we may let it remain. As a guide to psychological research, it seems to anyone who is familiar with the false clues of the past to stand on the same level of usefulness as the project of the Laputan philosopher to extract sunshine out of cucumbers.

\section{Obituary.}

\section{Dr. Enrico SEREnI.}

THE sudden death of Enrico Séreni, at Naples on Mar. 1, ends prematurely, at the age of thirty. years, a career full of scientific usefulness and promise. Sereni had been in charge since 1926 of the section of physiology at the Zoological Station at Naples, and so was well known to the many biologists who worked there. To his British physiological friends and colleagues he was better known from having spent a large part of 1924 in London at University College, and from having travelled with them to and from the International Congress 